\title{
Um relato para lembrar Darcy Ribeiro
}

\author{
Gisele Jacon de Araújo Moreira - Fundação Darcy Ribeiro (FUNDAR)
}

\section{Resumo}

Este é o meu relato sobre o trabalho intelectual e literário de Darcy Ribeiro entre 1991 e fevereiro de 1997, quando faleceu, período em que fui sua assessora técnica, contribuindo na elaboração, organização e edição de textos e livros de sua autoria. Durante seu mandato de senador, a escrita foi a principal arma usada por Darcy para difundir uma consciência crítica dos problemas que o Brasil enfrenta. Apresento aqui a rotina e os hábitos deste intelectual e romancista naquele período, sempre influenciado pelo profundo desejo de beleza que adquiriu durante os anos de convivência com os índios. Diagnosticado com um câncer terminal, o escritor Darcy Ribeiro descansava do intenso trabalho intelectual e senatorial escrevendo poesias e uma autobiografia.

\section{Palavras-chave}

Darcy Ribeiro; Produção literária; O povo brasileiro, Povos indígenas.

\section{A narrative to remember Darcy Ribeiro}

\begin{abstract}
This is my account of the intellectual and literary work of Darcy Ribeiro between 1991 and February 1997, when he died, period in which I was his technical advisor, contributing to the preparation, organization and editing of essays and books of his own. During his mandate as Senator, writing was the main weapon used by Darcy to spread a critical awareness of the problems facing Brazil. I present here the routine and the habits of this intellectual and novelist in that period, always influenced by the deep desire for beauty that he acquired during the years of living with the Indians. Diagnosed with terminal cancer, the writer Darcy Ribeiro rested of the intense intellectual and senatorial work by writing poetry and an autobiography.
\end{abstract}

\section{Keywords}

Darcy Ribeiro; Literary production; The Brazilian people; Indigenous peoples.

\section{Um relato para lembrar Darcy Ribeiro}

"Se procurar bem você acaba encontrando.

Não a explicação (duvidosa) da vida, Mas a poesia (inexplicável) da vida." Carlos Drummond de Andrade ${ }^{1}$

Fui assessora técnica do professor Darcy Ribeiro durante seis anos, entre 1991 e sua morte em fevereiro de 1997. Durante aqueles anos me dediquei a colaborar na elaboração, organização e edição de seus textos, ensaios e livros. Nos últimos anos, cada vez mais absorvida pela produção intelectual e pelas diversas atividades de Darcy Ribeiro, assumi também funções de secretaria no escritório que o então senador mantinha em seu apartamento no Rio de Janeiro. 
Durante seu mandato de senador, a escrita foi a principal arma usada por Darcy para difundir uma consciência crítica dos problemas que o Brasil enfrentava. Gostava de ser senador e dizia que "estar no senado é como estar no céu, mas com a vantagem de não precisar morrer para estar lá". ${ }^{2}$ Era o lugar onde podia discutir os desafios do país e defender ideias, projetos e planos para melhorar o Brasil.

Com estilo próprio e indignado, em seus pronunciamentos e falas no Senado, dirigia-se ao chefe do poder executivo, buscando sensibilizá-lo com exposições contundentes sobre os mais graves problemas que afligiam a sociedade brasileira. Dedicou-se a veicular entre os parlamentares e formadores de opinião artigos e ensaios reunidos na revista Carta': falas, reflexões, memórias, publicação de seu gabinete que atendia uma das funções do parlamento, a de divulgar informação bem fundamentada sobre temas de interesse nacional. ${ }^{3}$

Foi, provavelmente, um dos períodos mais fecundos de sua longa trajetória de pensador do Brasil, resultando na elaboração de seis livros, o mais lido deles, com inúmeras reedições, O Povo Brasileiro, publicado em 1995, concluiu a série de cinco volumes de seus Estudos de Antropologia da Civilização, iniciada na década de 1960.

É preciso compreender que Darcy atuou em várias áreas ao longo da vida, na etnologia, na antropologia, na educação, na literatura e na política, relacionando-se com diversas instâncias do poder e da sociedade, desde caboclos e índios da Amazônia, até presidentes, ministros, parlamentares. Era, ao mesmo tempo, um intelectual e um bom executivo. Cada testemunho, portanto, de seus inúmeros colaboradores, assessores e assistentes seleciona ou destaca diferentes experiências ou facetas desta personalidade complexa.

Uma característica em particular saltava aos olhos, sua compreensão esclarecida sobre as urgências do país e o engajamento em experiências políticas necessárias para o desenvolvimento pleno e autônomo do Brasil. Seus colaboradores convertiam-se em participantes de programas verdadeiramente essenciais para a formação intelectual comprometida com os rumos do país, atuando organicamente em projetos de transformação ampla.

Essa qualidade de Darcy, tão evidente para aqueles que com ele conviveram mais de perto, de unir o entendimento e o "fazimento", o pensar e o fazer em causas legítimas para a sociedade brasileira, foi brilhantemente destacada por Antonio Candido, na citação a seguir:

O caso especial de Darcy é que, além de ser um intelectual de muita eminência, um intelectual que construiu uma obra de antropólogo, de educador e de escritor, ele tem uma grande capacidade de ação - essa coisa rara que é a fusão do intelectual e do homem de ação, qualidades que geralmente encontramos dissociadas e que nele estão não apenas unidas, mas unidas de uma maneira construtiva, de uma maneira harmoniosa, que the permite servir a seu país com uma amplitude e uma intensidade de que 
temos poucos exemplos na nossa história mental e na nossa história política. Por que isto? Porque Darcy consegue aliar uma grande eminência intelectual à capacidade de atuar não em sentido qualquer, mas no sentido dos interesses mais legítimos da sociedade.

Antonio Candido - depoimento sobre Darcy Ribeiro gravado em 12 de outubro de $1996^{4}$

\section{O intelectual}

Quando, em 1991, comecei a trabalhar com Darcy Ribeiro, esperava aproximar-me de um grande intelectual, o antropólogo brasileiro, reconhecido em todas as universidades latinoamericanas, autor de uma Teoria da Antropologia da Civilização, que compreendia quatro alentados livros acadêmicos - O processo civilizatório, A América e a Civilização, O Dilema da América Latina, Os Índios e a Civilização -, que trabalhou com Rondon no antigo Serviço de Proteção aos Índios e que criou o Museu do Índio.

Assustei-me com minha falta de habilidade para o cotidiano de um homem pragmático, pouco afeito a me deixar divagar, a permitir diletantismos intelectuais. Adentrei no mundo do trabalho efetivamente, arrancada de anos de estudo, aulas, vida universitária e pesquisa antropológica.

Inicialmente, atendi na representação do Senado Federal no Rio de Janeiro, que ficava em um prédio anexo ao Palácio do Itamaraty. Dali, era regularmente chamada para reuniões ou encontros com Darcy em sua residência, em Copacabana, ou na Secretaria Extraordinária de Programas Especiais do governo do Estado do Rio de Janeiro, localizada em São Cristóvão. Em pouco tempo, entretanto, fui compelida por ele a permanecer trabalhando no escritório de sua residência, disponível para atendê-lo mais constantemente.

Durante o mandato senatorial, Darcy Ribeiro licenciou-se duas vezes por razões políticas. Na primeira, no final de agosto de 1991, a pedido de Leonel Brizola, então governador do Rio de Janeiro, assumiu a Secretaria Extraordinária de Programas Especiais, responsável pela implantação de 500 Centros Integrados de Educação Pública - CIEPs. Retornou ao Senado em maio de 1992. Na segunda licença, por um curto período, participou da campanha presidencial de Brizola como candidato a vice, em 1994. Em nenhum destes interregnos, ele parou de produzir e escrever cotidianamente. Mudávamos nós, seus colaboradores ou assessores, de local de trabalho ou de reuniões e encontros.

O primeiro livro em que trabalhei com o Professor, como eu o chamava - ou Mestre, como era referenciado por outros -, A Fundação do Brasil: testemunhos de 1500 a 1700, foi uma obra 
elaborada em coautoria com o etnohistoriador Carlos de Araujo Moreira Neto sob encomenda da prestigiosa Fundação Biblioteca Ayacucho, da Venezuela. Durante todo o ano de 1991 me dediquei a apoiar o trabalho intelectual de Carlos Moreira, antigo aluno e assessor de Darcy Ribeiro: identificando os testemunhos de época, buscando cópias das primeiras edições em bibliotecas ou em publicações, selecionando os trechos de interesse e digitando e organizando os textos. Fazíamos reuniões frequentes com Darcy, em que o sumário do livro era arranjado de acordo com as visões e interesses de cada um dos testemunhos (oficiais, religiosos, empresariais, aventureiros, franceses e outros). Carlos Moreira elaborou notas introdutórias sobre cada um dos textos-testemunho.

Além disso, Darcy queria uma cronologia daquele espaço temporal de 200 anos, justapondo dados culturais, eventos, conflitos e personagens importantes da história do Brasil, da América e do mundo, ano a ano, com o duplo objetivo de resumir sistematicamente os fatos mais significativos relatados no livro e compará-los com os acontecimentos simultâneos da história universal. Fui autora deste Sincronótico, orientada por Darcy Ribeiro de acordo com um esquema semelhante àquele que adotara em seu livro Aos Trancos e Barrancos, como o Brasil deu no que deu, publicado em 1985, e que compreendia o período de 1900 a 1980.

Após organizar todo o livro, entreguei a Darcy os originais e um resumo esquemático de toda sua estrutura. No início de 1992, durante apenas uma semana, para meu espanto, Darcy elaborou e ditou a introdução ao livro, intitulada “A invenção do Brasil”. Um dos textos mais belos e expressivos que já li sobre a formação do Brasil.

O livro também foi publicado no Brasil, pela editora Vozes, no final de 1992. O formato quadrado, o tamanho e a diagramação do livro, com o texto em duas colunas, foram opção de Darcy, o que exigiu de mim um trabalho insano, com meus parcos recursos de informática, além do editor de texto, para montar em word o miolo do livro. Durante várias semanas do ano de 1992, fui acolhida por servidores da Secretaria de Tecnologia da Informação - Prodasen e da gráfica do Senado para que pudesse concluir o trabalho.

Dois anos depois, abatido após internação em Unidade de Terapia Intensiva com pneumonia, diagnosticado com câncer, Darcy resolveu dedicar-se à conclusão de outro livro que exigiria um grande esforço intelectual, a obra que completaria sua série de Estudos de Antropologia da Civilização, com O Povo Brasileiro.

Saiu do hospital e partiu direto para sua casa de praia em Maricá, onde poderia estar recluso para se recuperar fisicamente e para se dedicar àquele novo desafio intelectual. Durante o mês de janeiro e parte de fevereiro de 1995, acompanhei-o nesta tarefa. Às segundas-feiras pela manhã, seguia para Maricá, onde passava a semana, retornando ao Rio na sexta-feira seguinte. 
Improvisamos um ambiente de trabalho na casinha de Maricá, construída em forma de meia lua, com todos os cômodos abertos para uma pequena piscina, de frente para o mar.

Não faltava, também lá, uma biblioteca, onde instalei o Macintosh, organizei os materiais que precisávamos e as pastas com versões anteriores do livro. Passávamos o dia trabalhando, com pequenos intervalos. Após o almoço, ele repousava um pouco. À noite, jantávamos e Darcy lia, descansava, conversava antes de dormir. Tinha premência em concluir o livro, estava concentrado, impacientava-se e abreviava visitas - muitas, amigos queriam vê-lo após sua internação, quando quase morreu na UTI do hospital.

O livro tinha uma versão inicial, inacabada, escrita ainda no exílio no Peru. E outras versões, reescritas ao longo de trinta anos, sem conclusão, procurando entender por que o Brasil não deu certo. Essa explicação resultou numa série de livros que compõem o marco teórico - Teoria de Antropologia da Civilização - que Darcy ousou construir para situar a experiência histórica do Brasil na história humana (O Processo Civilizatório), no processo de formação e desenvolvimento desigual dos povos americanos (As Américas e a Civilização) e no contexto do dilema latinoamericano da pressão hegemônica norte-americana (O Dilema da América Latina).

Durante dois meses, entre janeiro e fevereiro, trabalhamos quase cotidianamente no livro e ele foi finalizado, com índice remissivo, e entregue à editora Companhia das Letras em março de 1995, publicado em abril para gozo de Darcy Ribeiro. Suas duas primeiras partes, O Novo Mundo e Gestação Étnica compõem uma versão mais completa e profunda da introdução de Darcy Ribeiro para o livro A Fundação do Brasil, testemunhos de 1500-1700, mencionado anteriormente. As demais partes do livro prolongam no espaço e no tempo a interpretação do autor sobre a formação de um povo novo, o povo brasileiro contemporâneo e suas versões regionais culturalmente moldadas - o Brasil crioulo, caboclo, sertanejo, caipira, sulino -, concluindo de forma otimista com a versão do destino nacional como o de uma nova Roma.

Não houve sofrimento durante essa elaboração, Darcy já estava impregnado de uma interpretação sobre o Brasil e as causas de seus problemas. Mas foi bastante trabalhoso, com muitas leituras, releituras e revisões. Os capítulos sobre $A$ urbanização Caótica, Classe, Cor e Preconceito, Assimilação ou Segregação e Ordem versus Progresso, da parte III - Processo Sociocultural - foram os que mantiveram quase integralmente as versões anteriores. Os capítulos mais alterados foram os capítulos iniciais, partes I - O Novo Mundo - e II - Gestação Étnica, bem como os capítulos finais, em particular o último, O Destino Nacional, que conclui a parte IV - Os Brasis na História. Todos os dados e informações importantes já estavam na versão anterior e não tivemos que recorrer a outras fontes, além daquelas que compunham as referências bibliográficas prévias. 
Inicialmente fizemos uma leitura integral, em voz alta, da versão escrita no Peru, que já estava digitada. Eu lia em voz alta a partir do computador e Darcy acompanhava no papel. Interrompia, ditava acréscimos, alterava trechos, reorganizava a ordem dos parágrafos ou de trechos do livro.

Geralmente, enquanto ele repousava, eu inseria algumas correções e revisões indicadas por ele. Me angustiava um pouco estarmos tão longe do atendimento médico, caso houvesse alguma urgência, mas nos acompanhava um enfermeiro. Durante as leituras do livro, eu ficava de costas para Darcy, que sentado ou deitado em um sofá, acompanhava com os papéis na mão. Às vezes, ele estava muito mudo e eu virava para vê-lo, preocupada de que estivesse passando mal. Apenas cochilava!

Tivemos entreveros nesta estadia em Maricá. Sobretudo porque ele me infernizava com a alimentação. Eu não como carne e era reprovada constantemente pelos olhares e meneios de cabeça do professor, indignado com meu desprezo pelas carnes e peixes que seu cozinheiro Cícero tão bem preparava. Dizia que eu não sabia o que era bom na vida. Ele comia feliz, cheio de exclamações entre uma garfada e outra

Em um final de semana, o Cícero cozinheiro acabou desentendendo-se com o enfermeiro e partiu para as vias de fato, fora de si e cheio de raiva. Foi dispensado e tivemos muita dificuldade em continuar atendendo às exigências culinárias de Darcy. Eu em particular, porque não sirvo nem para fritar um ovo.

\section{O romancista}

Sou mesmo é escritor, cobaia a ser escrutinado. O que posso dar são testemunhos como este. Duvidosos.

Darcy Ribeiro, Maíra, um romance dos índios e da Amazônia. 1996: 23

A forma literária do romance foi adotada por Darcy para sair do esgotamento intelectual em que submergiu durante a elaboração de $O$ processo civilizatório, um dos livros da Série de Antropologia da Civilização, na década de 1960, quando estava no exílio, no Uruguai. De acordo com seu próprio depoimento na introdução da edição comemorativa dos 20 anos de Maíra, publicada em 1996, era uma cura para a incapacidade de produção intelectual mais sistemática. A escrita do romance Maíra surge para ocupar a cabeça com um outro polvo. É curioso que Darcy associasse a produção literária ao descanso do trabalho intelectual. Mas se divertia deixando a imaginação fluir em golfadas no primeiro caso, no segundo, ao contrário, conduzia a produção a partir de uma programação elaborada intelectualmente. 
Maíra, sua obra literária mais conhecida, não foi o primeiro romance que escreveu. Ainda na juventude, pretendia ser escritor e poeta. Na década de 1940, aos vinte anos, em Minas Gerais, escreveu seu primeiro romance, intitulado Lapa Grande, que submeteu a um concurso da Editora José Olympio e foi rejeitado, ficando inédito: "Felizmente inédito, e aqui proíbo terminantemente a qualquer aventureiro publicá-lo, em qualquer tempo" (RIBEIRO, 1997:95).

Publicou outros três romances - O Mulo, Utopia Selvagem e Migo - e, sem vergonha, aventurou-se até na poesia ao final. Se bem que esse gênero já estivesse presente nos seus escritos, como no romance Migo, publicado em 1988, que remete à mineiridade.

Pouco antes de morrer, Darcy estava dedicado a um novo romance. Me disse que era sobre um michê em Copacabana. Neste caso, ele não ditava nada, estava no casulo, utilizando apenas a caneta e um caderno, rascunhando sua nova criação. Esse romance nunca foi concluído e o manuscrito faz parte do acervo da Fundação Darcy Ribeiro.

Os poemas, entretanto, escritos já com conhecimento do câncer terminal, foram publicados postumamente no livro Eros e Tanatos. Todos escritos à mão, geralmente à noite, foram entregues para digitação e as páginas impressas ficavam em sua mesa de centro, na sala. Eram revisados pelo autor com frequência. Eventualmente acrescentava mais algum. Submeteu à análise crítica de amigos e não se decidiu pela publicação em vida. Foram publicados postumamente, pela Fundação Darcy Ribeiro, com posfácio do poeta e escritor Moacyr Felix.

Também se aventurou na literatura infanto-juvenil com dois livros no período de seu mandato senatorial. O primeiro, publicado em 1995, é um conjunto de ensaios curiosos, irônicos e críticos, sobre diversos assuntos: os índios, os números, as pulgas, o fim do mundo, o Brasil... Não por acaso, o título deste livro é Noções de coisas, parodiando ironicamente Lições de Coisas de Rui Barbosa, que ele chamou de "o maior coco da Bahia". Darcy não teve filhos e dizia que não teve que domesticar ninguém. Mas gostava de crianças e era completamente "sem noção" com elas. Numa das vezes em que esteve com meu filho, que tinha entre oito e nove anos na época, cantou uma música cheia de termos escatológicos pedindo que o menino repetisse com ele.

O outro livro eram duas deliciosas e irreverentes histórias infantis sobre uma comunidade de gatos, as Histórias Gáticas, ilustradas lindamente por Patrícia Gwinner. Era uma brincadeira feliz, nos divertíamos muito. Durante muito tempo, Patrícia deixava desenhos e mais desenhos para Darcy na portaria do prédio, remetendo ao enredo da gataria. Todos guardados cuidadosamente. O livro foi finalmente publicado, postumamente, pela FTD, em 2002.

\section{O desejo de beleza}


Darcy Ribeiro estava sempre atento à estética das coisas. Sua criação era singular porque continha o desejo de beleza, característica que deve ter herdado dos índios - com os quais conviveu em longas expedições de campo como etnólogo do Serviço de Proteção aos Índios, após formarse na Escola de Sociologia e Política de São Paulo - e exerceu em cada uma de suas atividades. Na escrita, revelava cuidado com as edições e ilustrações de seus livros. Em casa, sempre tinha arranjos de flores na sala. A bela visão da praia de Copacabana que uma simples reforma no seu apartamento divisou, as obras e objetos de arte dispostos nas estantes, que cobriam as paredes da sala, abrigando sua biblioteca. As construções que planejou com Oscar Niemeyer para seus projetos. Sempre almejando a beleza na vida.

"Não havendo para os índios fronteiras entre uma categoria de coisas tidas
como artísticas e outras, vistas como vulgares, eles ficam livres para criar
o belo. Lá uma pessoa, ao pintar seu corpo, ao modelar um vaso, ou ao
trançar um cesto, põe no seu trabalho o máximo de vontade de perfeição e
um sentido desejo de beleza só comparável com o de nossos artistas
quando criam. Um índio que ganha de outro um utensílio ou adorno ganha,
com ele, a expressão do ser de quem o fez. O presente estará ali,
recordando sempre que aquele bom amigo existe e é capaz de fazer coisas
tão lindas." (RIBEIRO, 1997:160).

Eventualmente, queria que eu o acompanhasse em eventos ou reuniões, instrumentada como se deve para essas ocasiões. Nem pensar em levar uma pasta de "poliondas" na mão horrorosa! -, papéis amarfanhados, relatórios sem capa, bloco medíocre para anotações. Tinha sempre uma papelaria em casa, com cartões impressos com seu nome, envelopes, papéis timbrados e preferências na diagramação de suas correspondências e dos textos de sua autoria.

Outra atividade, que acabei adotando também por simpatia, era a dedicação e o cuidado que mantinha com suas agendas, anotando observações e colando ali pequenas notas de jornal sobre seus livros ou seus feitos, fotos ou outras ilustrações.

Gostava de usar as canetas hidrográficas, com ponta porosa, porque exigiam menos esforço da mão ao escrevinhar. A letra, que já era difícil, com o passar dos anos foi piorando. Tanto que, às vezes, nem ele entendia o que havia escrito. Mas usava uma caneta mont blanc no Senado ou em eventos públicos.

Quando enviava cartões para amigos, ou livros autografados, pedia para que eu incluísse uma tradução impressa em computador dos seus dizeres, facilitando a leitura dos destinatários. Em uma ocasião, enviou um pequeno texto para uma antiga amiga. Imediatamente, adicionei a transcrição. Passados alguns dias, ele me chamou e perguntou se eu havia traduzido seu cartão antes de enviar e eu confirmei. Ele me olhou, surpreso e esclareceu: aquele, em especial, não era para transcrever. Afinal, a amiga era casada! 
Em 1992, passei a me ocupar também, entre outros, da edição da revista Carta' um informe de distribuição restrita do gabinete do Senador Darcy Ribeiro. Em 1993, proclamado pela Assembléia Geral das Nações Unidas como o Ano Internacional dos Povos Indígenas, publicamos o número 9 da revista sobre os índios do Brasil. Nessa publicação, a pedido de Darcy Ribeiro, organizei a edição de trechos dos diários do indigenista João Evangelista Carvalho sobre $A$ Pacificação dos Parakanã. João Evangelista fora intérprete de Darcy Ribeiro em suas pesquisas de campo junto aos índios Urubu-Kaapor, da fronteira maranhense da Amazônia, entre 1949 e 1950.

A partir de então, cresceu em Darcy a vontade de publicar seus próprios diários de campo naquelas duas viagens de seis meses cada entre os Kaapor, que ele considerava remanescentes dos Tupinambá do primeiro século de colonização que, depois das primeiras décadas de contato devastador com a civilização, teriam se escondido mata adentro para sobreviver.

Os Diários, em cadernos manuscritos, haviam sido remetidos a sua então esposa, Berta Ribeiro, que os datilografara. Havia, também, muitas fotografias daquelas viagens, algumas registradas pelo fotógrafo e cineasta Heinz Foerthamn, que acompanhara as expedições. Na edição, cotejamos todo o material datilografado com os cadernos originais. Na margem dos textos, inserimos fotos que retratavam os personagens ou ilustravam os assuntos relatados. Para facilitar a leitura, identificamos, também à margem dos textos, os temas ali abordados. Ao final, criamos índices de fotos, dos mitos relatados, dos diagramas de parentesco e genealogias, de quadros e mapas e de gravuras e desenhos. Resultou numa belíssima edição, cheia de imagens do jovem e desbravador etnólogo Darcy Ribeiro entre os índios na Amazônia!

\section{O "Trickster"}

Não sou bom no sentido cristão, de bondade caridosa. Essa de contentarse em dar uma escolinha boa ou uma sopa para os famintos. Odeio essa postura dadivosa, que só serve para consolar os culpados da ignorância e da pobreza generalizadas. Quero é fartura para todos comerem, para crescerem sadios e manterem seus corpos. Quero é boas escolas, para a criançada toda, custe o que custar, porque não há nada mais caro que o suceder de gerações marginalizadas pela ignorância. Quero é lotear essa metade do Brasil possuída pelos fazendeirões que nunca plantaram, nem pretendem plantar, para entregá-la em milhões de fazendinhas familiares à gente que se estiola desempregada e decaída na pobreza e na criminalidade. Encanta-me sonhar com o que seria a Amazônia, com a mata devolvida aos caboclos, que são o povo da floresta, para ali se assentarem tão sabiamente como os franceses se assentam na França para produzir queijo de cabra e vinho. (RIBEIRO, 1997: 525-526) 
As lembranças mais recorrentes que tenho daqueles anos de trabalho intenso são de Darcy afundado em sua poltrona Wassily preta na sala de seu apartamento, lendo ou escrevendo, sobretudo refletindo e escrevendo com os papéis no colo. Escrever era sua atividade principal. Sentia que, além de instrumento de trabalho, a escrita já encarnava em Darcy como registro, como posteridade, como confissão de vida. Evidentemente, passava muito tempo também dedicado aos seus ofícios e cargos, no gabinete em Brasília, participando de seminários ou eventos oficiais, culturais, universitários.

Era um homem solitário, sem esposa, sem filhos, dedicado integralmente ao trabalho, com que se ocupava e se distraía escrevendo. Quando ia para a casa de praia em Maricá, nos finais de semana, me pedia livros policiais emprestados. Leu alguns de Agatha Christie e toda minha coleção de Arsène Lupin. Quando devolveu, percebi que em vários exemplares, no verso da quarta-capa, Darcy anotara diagramas de parentesco dos personagens. Provavelmente para não esquecer quem era quem.

Antropólogo, educador, político e escritor: toda a produção acadêmica, intelectual e literária de Darcy Ribeiro foi marcada, entretanto, pelo seu trabalho como etnólogo nas décadas de 1940 e 1950, período de intenso convívio com os índios do Pantanal e da Amazônia e de conhecimento das populações regionais daqueles rincões do Brasil.

Darcy Ribeiro dizia que os índios, aos poucos, o foram "desasnando", fazendo com que os visse não como objeto de estudo externo, que se olhava desde fora, mas como gente que eram. Gente capaz de dor, de tristeza, de amor, de gozo, de desengano, de vergonha. Gente que sofria a dor suprema de ser índio num mundo hostil, mas guardava no peito um orgulho de si mesmos como índios. Gente muito mais capaz que nós de compor existências livres e solidárias, adaptando-se penosamente aos novos tempos para sobreviver tal qual é ou era.

"Quando digo que sou socialista, o socialismo que sonho é o de uma civilização avançada, com esse talento índio da convivência e da solidariedade. Creio que no convívio com os índios eu me refiz, o que aprendi com eles é talvez o que me singulariza entre os intelectuais de minha geração. Aos índios devo, também, a dignidade que me deu a luta que travo há quarenta anos para salvá-los.” (RIBEIRO, 1995: 305)

Em 1996, com o agravamento de sua saúde, Darcy Ribeiro estava ansioso por legar seu patrimônio e direitos autorais para a Fundação que criou e fazia muitos planos e projetos que queria ver concretizados por meio daquela instituição. Emitiu correspondência para todas as editoras nacionais e internacionais de seus livros, comunicando que a Fundação Darcy Ribeiro passaria a ser detentora dos direitos de suas obras, com o objetivo de manter edição e reedição de seus livros. 
Entre os projetos, estava o da Universidade Aberta de educação a distância que, com a aprovação da nova Lei de Diretrizes e Bases da Educação Nacional ${ }^{5}$, seria passível de implantação. Ainda na área de educação, e vinculada a este projeto maior de Universidade, ele pretendia criar uma Escola Normal Superior para a formação de professores do ensino fundamental, também prevista no nova Lei de Educação.

Outro projeto importante para Darcy nos estertores de sua atuação, foi o Projeto Caboclo, "um plano alternativo de ocupação da Amazônia". Havia muitos anos que vinha tentando implementar este projeto. Pretendia deixá-lo estrategicamente planejado sob o amparo de cientistas e pesquisadores que convidou para constituir uma Comissão Científica interdisciplinar que orientaria suas ações. Ele faleceu no dia mesmo em que apresentaria seus planos a essa Comissão, que se encontrava reunida em Brasília para o $1^{\circ}$ Simpósio da Amazônia. Internado no Hospital Sarah Kubitschek desde a quinta-feira anterior, Darcy não pode sair do hospital no domingo, como pretendia, para presidir o Simpósio na segunda-feira, dia 17. O Simpósio transcorreu sem sua presença e, no final da tarde, logo após o encerramento, Darcy Ribeiro faleceu no hospital. Foi um dia tenso e exaustivo para nós, seus colaboradores, em particular, porque antevimos o fim, mantendo, no entanto, a programação que ele cuidadosamente planejou.

Herdamos muitas missões e continuamos tentando realizá-las com a Fundação Darcy Ribeiro. Em 1995, Darcy tratou de fazer um testamento, dispondo de seus bens após sua morte, em grande parte para a Fundação. Ali está registrada a marca de sua rebeldia, fazendo inscrever que o cavalo preto, habitante do seu sítio em Maricá, seria aposentado, livre para pastar todo o capim que conseguisse até o fim da vida.

\section{Referências Bibliográficas}

COELHO, Haydée Ribeiro (org.). Darcy Ribeiro. Belo Horizonte: Centro de Estudos Literários da UFMG; Curso de Pós-Graduação em Letras - Estudos Literários, 1997.

RIBEIRO, Darcy. O processo civilizatório. Etapas da evolução sócio-cultural (Série de Estudos de Antropologia da Civilização). Rio de Janeiro: Civilização Brasileira, 1968.

------- As Américas e a civilização. Processo de formação e causas do desenvolvimento desigual dos povos americanos (Série de Estudos de Antropologia da Civilização). Rio de Janeiro: Civilização Brasileira, 1970.

------- Os índios e a civilização. Integração das populações indígenas no Brasil moderno (Série de Estudos de Antropologia da Civilização). Rio de Janeiro: Civilização Brasileira, 1970.

------- O dilema da América Latina. Estruturas de poder e forças insurgentes (Série de Estudos de Antropologia da Civilização). Petrópolis: Vozes, 1978.

Migo. Rio de Janeiro: Guanabara, 1988. 
O povo brasileiro. A formação e o sentido do Brasil (Série de Estudos de Antropologia da Civilização). São Paulo: Companhia das Letras, 1995.

-------- O Brasil como problema. Rio de Janeiro: Francisco Alves, 1995.

Noções de coisas. São Paulo: FTD, 1995.

Diários índios. Os Urubus-Kaapor. São Paulo: Companhia das Letras, 1996.

Confissões. São Paulo: Companhia das Letras, 1997.

Eros e Tanatos. A poesia de Darcy Ribeiro. Rio de Janeiro: Record, 1998.

RIBEIRO, Darcy; MOREIRA NETO, Carlos de Araujo. A fundação do Brasil. Testemunhos 15001700. Petrópolis: Vozes, 1992.

La fundacion de Brasil. Testimonios 1500 -1700. Caracas, Venezuela: Biblioteca Ayacucho, 1992.

\footnotetext{
${ }^{1}$ ANDRADE, Carlos Drummond de."Lembrete”, em Poesia Completa. São Paulo: Nova Aguilar, 2002: 1256.

${ }^{2}$ RIBEIRO, Darcy. Confissões, 1997: 491.

${ }^{3}$ Entre 1991 e 1996, foram publicados dezesseis números da revista:

Carta'1 (1991-1): Primeira fala ao Senado: raízes do atraso.

Carta'2 (1991-2): O Povo Latino-Americano.
}

Carta'3 (1991-3): Segunda fala ao Senado: dívida externa e política de privatizações; Teorias do Atraso e do Progresso.

Carta'4 (1992-1): Rio 92 - A vida em risco

Carta'5 (1992-2): Doutor Honoris Causa em Copenhagen; CIEPs: a Educação como Prioridade.

Carta'6 (1993-1): Formas e Sistemas de Governo.

Carta'7 (1993-2): Posse de Darcy na ABL; Nosso desafio energético; Marcas e Patentes.

Carta'8 (1993-3): O Brasil é viável?

Carta'9 (1993-4): 1993 - Ano Internacional dos Povos Indígenas - ONU.

Carta'10 (94-1): Salvemos a Nação Brasileira.

Carta'11 (1994-2): Nossa Herança Política.

Carta'12 (94-3): O descalabro educacional brasileiro

Carta'13 (94-4): 1695-1995 - 300 anos de Zumbi.

Carta'14 (1995-1): 1961-1995, A invenção da Universidade de Brasília.

Carta'15 (1995-2): O Novo Livro dos CIEPs

Carta'16 (1996-1): LDB - Lei de Diretrizes e Bases da Educação Nacional.

${ }^{4}$ Citado em COELHO, 1997: 168.

${ }^{5}$ Darcy Ribeiro foi autor da Lei de Diretrizes e Bases para a Educação Nacional, Lei No 9394/96, que mais tarde levaria seu nome em póstuma homenagem. A Lei foi sancionada pelo então Presidente da República Fernando Henrique Cardoso em 20 de dezembro de 1996. 